\title{
THE CUSHING OK CRUDE OIL FUTURES PRICE PASS - THROUGH TO NEW YORK HARBOR REFORMULATED RBOB REGULAR GASOLINE FUTURES PRICE
}

\author{
Chu V. Nguyen \\ University of Houston-Downtown, TX
}

\begin{abstract}
This study utilizes an Autoregressive Distributed Lag model to investigate the nature of crude oil futures price pass-through since 2006. The empirical results reveal a very high but incomplete short-run passthrough rate from the crude oil futures price to the gasoline futures price of 0.849298 with a corresponding negative long-run pass-through rate of -0.2440894 . These empirical findings suggest that traders in the U.S. oil and gasoline futures markets overreact to fluctuations in the crude oil futures price as evidenced by subsequent corrections made over the sample period. The result of the bounds test for a long-term relationship between these two futures prices is inconclusive. The empirical findings further suggest that U.S. futures market traders considered futures prices of gasoline three weeks earlier in determining the current trading price while taking only one week to respond completely to the shock in the crude oil futures price. The empirical findings of this investigation may address the core elements of the price dynamics of the crude oil and gasoline futures markets and advance inquiry into assessment tools that could manage a very complex market challenge, especially for policy makers in countries with transitional economies in Eastern Europe, Caucasus and Central Asia.
\end{abstract}

Keywords: Autoregressive Distributed Lag model, Crude oil futures price, Gasoline futures price, Futures price pass-through rate, Long-term relationship.

DOI: http://dx.doi.org/10.15549/jeecar.v4i1.151

\section{INTRODUCTION}

Gasoline, which is derived from crude oil, is arguably one of the most important commodities used in any modern industrial economy. In the age of globalization and given the outsourcing phenomenon, gasoline has been used more and more in emerging and transitional economies. Fluctuations in gasoline prices not only directly impact consumer spending habits but also have an effect on which cars consumers choose to buy and even how close they choose to live near their workplace. Central bankers in turn are concerned with how changes in gasoline prices impact inflation expectations, consumer spending, and consumer confidence (Yellen, 2011). The recent historic rise and fall in retail gasoline prices across the U.S. has led to greater interest in how the gasoline market works and how gasoline prices are determined. Cycles of gasoline prices now increasingly affect transitional and emerging economies.

Since the beginning of the industrial revolution, industrialized nations have had a relatively inelastic demand for petroleumbased products, particularly those used for 
energy and lubrication. Given this inelasticity of demand, prices are more sensitive to changes in supply which often leads to an increase in supply disruptions. In turn, higher petroleum prices result in cost-push inflation which reduces consumer real income and purchasing power and squeezes business profits. Because of this inherent regressive effect, these results often affect social welfare, causing a disproportionately severe negative income effect on the low income segment of the population. Historically, since the U.S. is dependent on imports for its petroleum requirement, high energy prices negatively affect the trade balance, the value of the U.S. Dollar, and the political and economic security of the nation.

During the energy crisis of the late 1970's and early 1980's, Kuuskra and Guthrie (2002) maintain that the U.S. government was actively involved in creating programs to promote energy independence. The Windfall Profits Tax Act in 1980, for example, created the Section 29 production tax credit for unconventional gas, providing an incentive of $\$ 0.50$ per thousand cubic feet of natural gas produced from unconventional resources.

Additionally, Trembath et al. (2012) posited that while private gas companies, particularly Mitchell Energy, did provide substantial inhouse $R \& D$ to the shale gas commercialization effort, federal programs were involved along every phase of the innovation pipeline. From early R\&D (diamond-studded drill bits, microseismic imaging, directional drilling) to cost-sharing on demonstration projects (the Eastern Gas Shales Project, the subsidization of Mitchell Energy's first horizontal drill in the Barnett) to tax policy support for a precommercial industry (the 1980-2002 Section 29 production tax credit for unconventional gas resources), federal agencies and policies have been in place for over 25 years to maximize the effect of shale gas research and commercialization.

Although unconventional gas production had been growing since the early 1980s, hydraulic fracturing technology had not been perfected or scaled to the point where full commercial deployment was competitive without subsidy. Shale gas production relied on the Section 29 production tax credit and on developers like Mitchell Energy charging a premium for gas resources. Mitchell Energy invested revenues in in-house R\&D throughout the 1980s and 1990s (Yergin, 2011). Having successfully demonstrated multi-fracture horizontal well drilling techniques in the Barnett, engineers had to develop the optimal combination of inputs water, proppants, chemical lubricants, etc. to achieve maximum gas recovery at the lowest cost possible.

\section{Gasoline Future Price, Crude Oil Future Price, and their Spread}

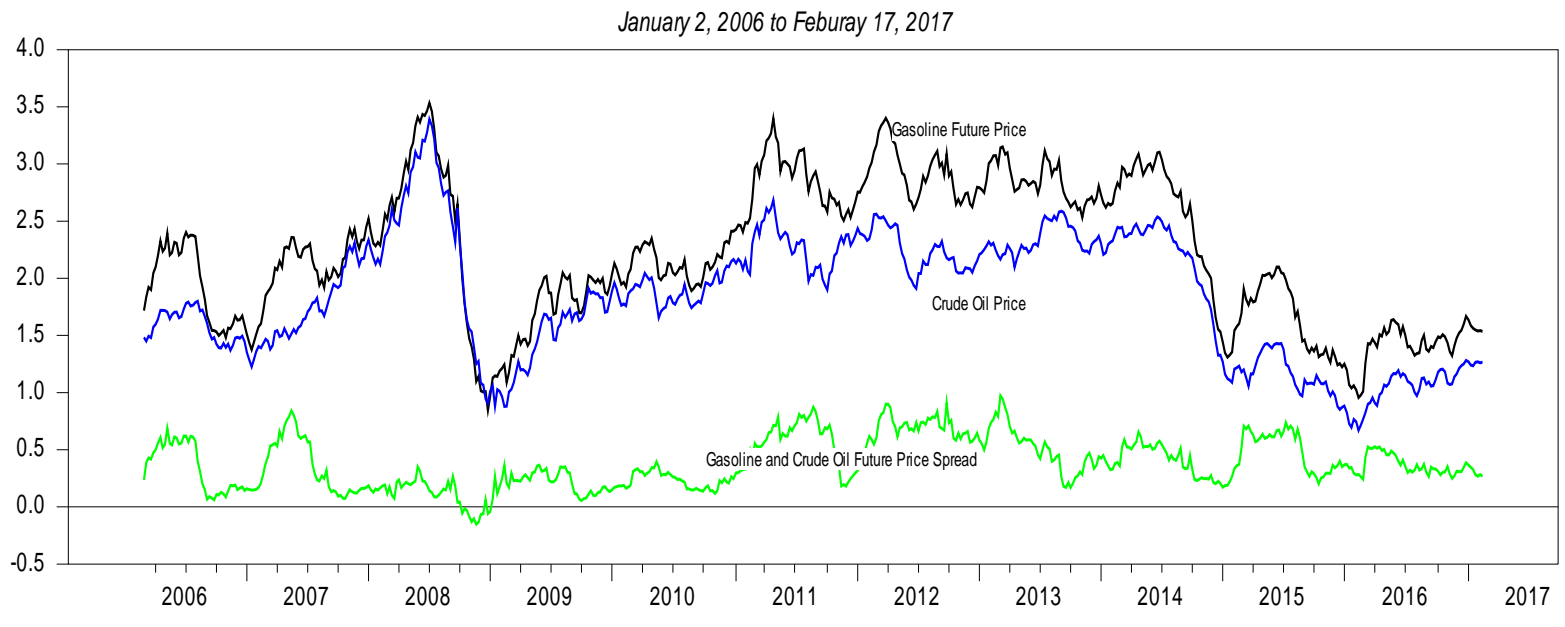

Figure 1. Gasoline, West Texas intermediate crude oil futures prices and their spread. 
In 1998, Mitchell Energy engineers applied an innovative well stimulation technique called 'slickwater fracturing' (or 'light sand fracking') that brought fracture job costs down to around $\$ 100,000$, compared to between $\$ 250,000$ and $\$ 300,000$ for massive hydraulic fracturing projects (Steinsberger, 2011). This is widely considered a milestone that pushed shale gas into full commercial competitiveness. Since that historical moment until now, the U.S. production of oil and gas has increased drastically while simultaneously reducing the US's dependence on crude imports significantly. As a historical note, Mitchell Energy was bought by Devon Energy in 2002 for $\$ 3.5$ billion, the same year that the Section 29 production tax credit was allowed to expire (Yergin, 2011).

Additionally, since the early 2000s, some large hedge funds have speculated on petroleum prices using derivative instruments having crude oil as the underlying commodity. Increases in prices could be partially due to this speculation activity extending into longer term instruments. These speculators foresee increasing demand, decreasing supply, or both, leading to the long term increase in the price of oil. If speculators are wrong, current prices may actually lead to a price bubble, which would ultimately collapse. It is theoretically expected that the rising oil market could quickly reverse, if indications of declining demand in Asia continue. These disruptions-coupled with limited stored gasoline supplies and the seasonality in demand, especially given American travel habits (particularly during the holidays)-may exacerbate the fluctuations in demand for fuels.

As to the oil needs of Eastern Europe and Central Asia, the International Energy Agency (EIA) (2016) argued that their convenient proximity to the world's fastest growing energy markets, particularly the resource-rich and transit countries of Eastern Europe, Caucasus and Central Asia (Armenia, Azerbaijan, Belarus, Georgia, Kazakhstan, Kyrgyzstan, Moldova, Tajikistan, Turkmenistan, Ukraine and Uzbekistan) contribute significantly to world energy security. However, shared challenges across the region include aged infrastructure, high energy intensity, low energy efficiency, untapped alternative energy potential and poorly functioning regional energy markets. These Countries cover a large geographic area of approximately 5 million square kilometers across central Eurasia, with a total population of 140 million. More than two decades after the break-up of the Soviet Union into 15 sovereign states with their declarations of independence, the levels of national sovereignty and the political and economic structures of these countries vary. However, they all share a recent Soviet past, from which they have inherited significant similarities in national economic design, governance structure, public institutions and infrastructure.

The post-Soviet period began with heavily interlinked industries and infrastructures, and fully integrated regional systems, preventing the newly independent states' functioning autonomously from one another. Augmented by the fact that their economies had been centrally governed during the Soviet era, none of these countries had the ability to master the full administrative spectrum of their internal or external affairs and were therefore left with sovereign authorities that had no leverage over the neighboring economies with which they were so strongly linked.

Since the break-up of the Soviet Union, the energy sector suffered the most among key segments of the economy in all the newly independent states. The energy markets that were originally set up to suit the overall Soviet planning were no longer effective. This was particularly evident for fixed energy infrastructures, designed to serve regional energy markets in the most rational way, which in some cases meant that countries had to cross the boundaries of neighboring countries to supply the more remote parts of their own territories.

Malfunctions in the previously centrally governed system operations at national level also became apparent from the outset. Energy systems became largely disordered in an attempt to nationalize previously commonly held assets. Energy companies were split into two segments: decision-making authorities that became the basis for energy ministries, and commercial operators, which were initially set up as vertically integrated national energy companies. Nations in the region - with the exception of Azerbaijan, Belarus, Tajikistan, Turkmenistan and Uzbekistan - national energy (electricity and natural gas) companies have undergone numerous waves of restructuring, commercialization and/or privatization proce- 
dures in an attempt to legally and/or commercially unbundle the energy sectors.

Pricing policies have moved from the ministries of economy to either sector ministries or dedicated regulatory agencies. These developments, in Armenia, Georgia, Kazakhstan, Moldova and Ukraine, resulted in the development of independent regulatory agencies during the mid to late $90 \mathrm{~s}$, with more elaborated market structures, market rules and tariff-setting methodologies. These early developments, however, did not provide enough footing for these newly established institutions to strengthen the development of energy markets.

In the mid to late 2000s (2006-08), a similar pattern was observed that government interference with electric utility companies jeopardized the independence of regulators, which were left to merely approve the tariffs dictated by direct contracts between the government and the energy companies. Recently, however, governments have been revising tariff structures, methodologies and set-ups in an attempt to relinquish their direct arrangements with energy companies and restore the independence of the regulatory authorities.

In countries where the government continues to set energy prices, at least one form of energy is subsidized. Pricing structures kept below the cost-recovery level therefore do not attract adequate investment to the sector, which in most cases is further encumbered with aged infrastructure in urgent need of upgrades and/or new, efficient system instalments. Energy subsidies, coupled with heavy public sector indebtedness in most of these economies, resulted in the energy sector's inability to generate adequate financial resources to maintain aging infrastructure to the necessary technical standards; most upgrade programmers are carried out as part of government-guaranteed long-term loans from international financial institutions. These practices further prevented energy system selfsufficiency, instead leaving many energy markets at the edge of collapse. Urgent and severe structural changes and reforms are required for the robust restructuring and revitalization of the sector.

Karimli, et al. (2016) observed that oil price shocks exert influence on domestic inflation through two main channels. The fiscal channel operates through government expenditures that are funded by oil revenues and the cost channel works through the price of imported goods and services. Intuitively, in times of oil price hikes, budget expenditures rise and aggregate demand is boosted in the country. On the contrary, falling oil prices hurt the terms of trade through more expensive imports and reduced budget expenditures.

The recent U.S. subprime mortgage crisis and excessive European sovereignty debt caused economic recession around the globe, slowing down the demand for gasoline in international markets, notably in China and India, providing a vivid example of causes of crude oil and gasoline price cycles. Additionally, the U.S. shale oil phenomenon of the past decade has created a condition that practically ensures crude oil price fluctuations as OPEC works harder to maintain market share. Simply put, as the price of crude rises, more shale oil volumes are brought into the market which in turn lowers the price to levels below which shale oil production is profitable. At that point, shale oil volumes are shut in, and with that curtailed supply, the crude oil price rises and in turn creates a recurrence of the cycle. Before the U.S. shale phenomenon, OPEC, and primarily Saudi Arabia, served as a swing producer increasing or decreasing production to stabilize markets. After abandoning that role and amid scores of other factors, the price of crude fell from over $\$ 100 /$ barrel to less than $\$ 40 /$ barrel. Recent policy readjustments by OPEC joined by major non-OPEC producers --such as the Russian Federation-- have brought some increase to crude oil markets. However, the overhanging shale production capability continues to persist so that wide price fluctuations, even though assured, are likely to fall within a narrower but still unpredictable range.

While the effects of petroleum price fluctuations are felt worldwide, countries in Eastern Europe and Central Asia are particularly affected, especially since several countries -notably, Azerbaijan, The Russian Federation, Kazakhstan, and Turkmenistan -- are important producers, and as all of the countries in the region are consumers. Additionally all are affected by the geopolitics of the region which is substantially underlain by petroleum markets, (e.g., the effects of the substantial loss of oil revenue on the Russian economy or the 
resurrection of Chinese interests in the resource rich Silk Road region). Fluctuations in crude oil prices and the concomitant effects on gasoline prices (and effectively by extension most other refined products) subject all countries to difficult choices in managing national expenditures, revenues, and investment decisions. Parallel effects challenge the private sector as well. Thus, it is useful to explore opportunities that mitigate the variations in such petroleum price fluctuations. Wide price swings may be beneficial to the speculative trader, but they are anathema to the public and private sector governing and management decision making process. Traditionally, futures markets evolved to mitigate such fluctuations. Understanding these futures markets and the nature of price reaction and price pass through lie at the center of and offer one approach to achieving more consistent, buffered, manageable economic continuity. This paper addresses the core elements of the price dynamics of the crude oil and gasoline futures markets and will hopefully promote the development of assessment tools designed to manage a very complex market challenge, especially for policy makers in Eastern Europe, Caucasus and Central Asia.

$$
S P_{t}=\mu+\theta D U+\alpha t+\gamma D T+\delta D\left(T_{b}\right)+\beta S P_{t-1}+\sum_{i=1}^{k} \psi_{i} \Delta S P_{t-i}+v_{t}
$$

where $\quad D U=1\left(t>T_{b}\right)$ is a post-break constant dummy variable; $t$ is a linear time trend; $D T=1\left(t>T_{b}\right)$ is a post-break slope dummy variable; $D\left(T_{b}\right)=1\left(t=T_{b}+1\right)$ is the break dummy variable; and $v_{t}$ are white-noise error terms. The null hypothesis of a unit root is stated as $\beta=1$. The break date, $T_{b}$, is selected based on the minimum t-statistic for testing $\beta=1$ (see Perron, 1997, pp. 358-359).

The common methodology to account for a structural break is to introduce a dummy independent variable $d_{t}$ with the value of 1 from the structural break date onward and 0 elsewhere. In the energy sector, a structural break is usually caused by a shock which precipitates an interaction between the

$$
\text { gas }_{t}=\mu+\sum_{j=1}^{n} \beta_{j} \text { gas }_{t-j}+\sum_{k=0}^{m} \delta_{k} w t i_{t-k}+\sum_{l=0}^{s} \rho_{l} z_{t-l}+\sum_{v=0}^{w} \pi_{v} d_{t-v}+\varepsilon_{t}
$$


where "gas ${ }_{t}$ " is the aforementioned gasoline futures price and " $w t i_{t}$ " is the crude oil futures price (dollar price per barrel divided by 42 ), at time $t$. As defined above, $z_{t}$ is an independent variable measuring the effect of the interaction between the structural break and the crude oil futures price. $d_{t}$ is the above defined dummy variable. $\delta_{0}+\rho_{0}+\pi_{0}$ is the short-run effect - within the week after the change in the crude oil futures price. It is a priory expectation that $0<\delta_{0}+\rho_{0}+\pi_{0} \leq 1$. $\delta_{0}+\rho_{0}+\pi_{0}<1$ indicates sluggish adjustment or stickiness. $\delta_{0}+\rho_{0}+\pi_{0}=1$ represents a complete pass-through in the short run.

Theoretically, the ARDL method proposed by Pesaran et al. (1997) has been a valuable tool for testing for the presence of long-run relationships between time-series. The advantage of the ARDL model is its ability to estimate both the long-term and short-term model parameters without requiring a pretesting to determine the order of the cointegration of the variables; thus, avoiding the problems posed by non-stationary time series. This pre-testing is particularly problematic in the unit-root cointegration literature where the power of the unit-root test is typically very low, and where there is a switch in the distribution function of the test statistics as one or more roots of the right hand side variables process approach unity. Furthermore, the ARDL procedure is robust with respect to small samples, allowing different optimal lags of variables.

However, Pereira and Maia-Filho (2013) argued that the bounds test is based on the assumption that variables are either $\mathrm{I}(0)$ or I(1). Therefore, it is prudent to determine the stationarity of the time series data. The

$$
\Delta g a s_{q}=\varphi+\sum_{j=1}^{n} \eta_{j} \Delta g a s_{-j}+\sum_{k=0}^{m} \kappa_{k} \Delta w t i_{t-k}+\sum_{l=0}^{s} \omega_{l} \Delta z_{t-l}+\sum_{v=0}^{w} \pi_{v} \Delta d_{t-v}+\lambda_{1} g a s_{-1}+\lambda_{2} w t i_{t-1}+\lambda_{3} z_{t-1}+\lambda_{4} d_{t-1}+\varepsilon_{t}
$$

where $\Delta$ is difference operator and the null hypothesis of "non-existing of the long-run relationship" is stated as $\lambda_{1}=\lambda_{2}=\lambda_{3}=\lambda_{4}=0$. The relevant $\mathrm{F}$ - most common testing procedures to test for stationarity of time series data are Kwiatkowski-Phillips-Schmidt-Shin and Phillips-Perron.

As to the empirical estimation, Enders (2015) suggested that the process to estimate the coefficients for equation (2) is to utilize the Akaike information criterion to select the largest values of $n, m, s$ and $\mathrm{w}$, deemed feasible; CUSUM test and CUSUM of Squares test are used to test for model stability. Breusch-Godfrey Serial Correlation Lagrange (LM) Multiplier Test is then used as diagnostics to test the hypothesis that the residuals $\left\{\varepsilon_{t}\right\}$ are white noise.

As articulated by Pereira and Maia-Filho (2013), given the estimation results for equation (2), the long- run effect or passthrough can be calculated as:

$$
\Phi=\frac{\sum_{k=0}^{m} \delta_{k}+\sum_{l=0}^{s} \rho_{l}+\sum_{v=0}^{w} \pi_{v}}{1-\sum_{j=1}^{n} \beta_{j}}
$$

As articulated by Berstein and Fuentes (2003), $\Phi$ should be positive and close to 1 . $\Phi=1$ implies a complete pass-through in the long-run. If $\Phi<1$ or $\Phi>1$, it implies either stickiness (less than perfect passthrough) or overshooting.

It is of interest to study the long-run relationship between the crude oil futures price and the gasoline price in the U.S. market to learn more about the nature of the impact of and oil shock in this economy. To this end, this investigation follows Pereira and Maia-Filho (2013) to use the bounds testing approach (Pesaran, Shin, and Smith, 2001) for the following error correction representation of the Autoregressive Distributed Lag model: 
variables are cointegrated. If it is below the lower bound, the null hypothesis cannot be rejected, i.e., there is no support evidence for long-run relationship between crude oil price and the gasoline price.

\section{DATA}

To study the nature of how changes in the crude oil futures price, are pass-through to the gasoline futures price and hence eventually to the consumers at the pumps, this investigation uses the Weekly New York Harbor Reformulated RBOB Regular Gasoline Futures Contract 1 Dollars per Gallon, denoted gas ${ }_{t}$ and the Weekly Cushing OK Crude Oil Futures Contract 1 Dollars per Gallon, denoted by $w t i_{t}$, from March 3, 2006 through February 17, 2017 (where the data is available) to estimate the autoregressive distributed lag model (2). The spread between these two prices is defined as their spread and is denoted by $P R_{t}$. All time series data are collected from the U.S. Energy Information Administration data bases.

\section{EMPIRICAL RESULTS}

The empirical results for this investigation are reported as follow.

\section{The Degree of Cointegration}

The bounds test is based on the assumption that variables are either $\mathrm{I}(0)$ or $\mathrm{I}(1)$. The most common testing procedures to test for stationarity of time series data are Kwiatkowski-Phillips-Schmidt-Shin and Phillips-Perron. The results of KwiatkowskiPhillips-Schmidt-Shin and Phillips-Perron test of the gasoline futures price, gas, and the crude oil futures price, $w t i_{t}$, are summarized in Exhibit 1. The Phillips-Perron testing procedure suggests that both futures prices are I(1) while the Kwiatkowski-Phillips-Schmidt-Shin test indicates that both of these two prices are I(0). Pereira and Maia-Filho (2013) argued that it is appropriate to use the bounds test to check for cointegration.

Exhibit 1. PP and KPSS Test Results, Oil and Gasoline Futures Prices, 2006:3:03 - 2017:2:17

\begin{tabular}{ccccc} 
& \multicolumn{2}{c}{ Phillips-Perron } & \multicolumn{2}{c}{ Kwiatkowski-Phillips-Schmidt-Shin } \\
Series & Level & Differencing & Level & Differencing \\
\hline gas ${ }_{t}$ & $-2.439743 \mathrm{n}$ & $-20.27926 \mathrm{y}$ & $0.400214 \mathrm{y}$ & $0.079046 \mathrm{y}$ \\
$w t i_{t}$ & $-2.147525 \mathrm{n}$ & $-19.68689 \mathrm{y}$ & $0.462506 \mathrm{y}$ & $0.087165 \mathrm{y}$ \\
\hline
\end{tabular}

Note: " ${ }^{\prime \prime}$ and ${ }^{\prime \prime}{ }^{\prime \prime}$ indicate whether the series is non- stationary and stationary 5 percent level.

\section{Structural Break}

The estimation results for Perron's (1997) endogenous unit root test function with the intercept, slope, and the trend dummy are summarized in Exhibit 2.

Exhibit 2. Perron's Endogenous Unit Root Test, Data - 2006:03:03 - 2017:2:17

$$
\begin{gathered}
P R_{t}=0.03277+0.07274 D U-0.00006 t-0.00007 D T-0.04818 D\left(T_{b}\right)+0.89282 P R_{t-1}+v_{t} \\
\left(3.29320^{*}\right) \quad\left(3.73051^{*}\right)(-1.02941)(-1.14262) \quad(-0.83141) \quad\left(51.15562^{*}\right)
\end{gathered}
$$

Number of augmented lags: $k=9 \quad$ Break Date: Jan. 28, $2011 \quad t(\alpha=1)=-6.14075 *$

Notes: Critical values for t-statistics in parentheses. Critical values based on $n=100$ sample for the break date (Perron, 1997). "“" indicates significance at 1 percent level.

The estimation results reveal that the postbreak intercept dummy variable, $D U$, is positive and is significant at any conventional level; while the post-break slope dummy variable,
$D T$, is negative and is insignificant at the 5 percent level. The break dummy, $D\left(T_{b}\right)$ is negative and is insignificant at any conventional level. The time trend, $t$, is negative and is 
An analysis of the overall estimation results indicates that there exists no serial correlation and that the model exhibits strong predictive power, as evidenced by the strength of the Breusch-Godfrey Serial Correlation Lagrange Multiplier Test $F(2,982)=0.729135$ with the p-value 0.4828 which fails to reject the null hypothesis that there is no serial correlation in the residuals. As Figure 1 illustrates, the CUSUM Test statistic and the CUSUM of Squares statistic fall entirely within the 5 percent level of significance. This empirical finding indicates the stabilities of the estimated parameters of the model over the sample period. Overall the diagnostic analysis indicates that the estimated $\operatorname{ARDL}(3,1,0,0)$ model is very reliable.
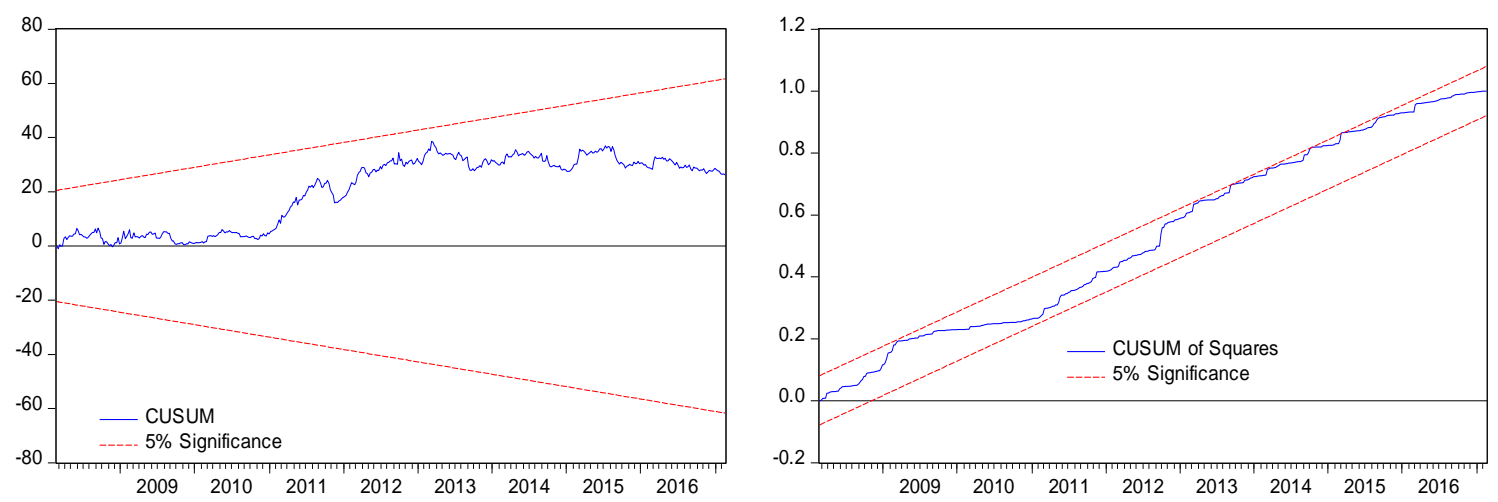

Figure 1: Graphic illustrations of CUSUM and CUSUM of Squares Tests to test for stability of model's estimated parameters.

As reported in Exhibit 3, the estimated sum of $\delta_{0}+\rho_{0}+\pi_{0}$ is $0.849298(0.866981+$ $0.032884-0.050567=0.849298)$. Also, using the estimated equation (3), the following calculation indicates that the estimated longrun crude oil futures price pass-through in the U.S. economy is $\Phi=-0.2440894$.

$$
\Phi=\frac{\sum_{k=0}^{m} \delta_{k}+\sum_{l=0}^{s} \rho_{l}+\sum_{v=0}^{w} \pi_{v}}{1-\sum_{j=1}^{n} \beta_{j}}=\frac{0.007813+0.032884-0.050567}{1-0.959564}=\frac{-0.00987}{0.0404360}=-0.2440894
$$

Finally, to test the null hypothesis of "nonexisting of the long-run relationship$H_{0}: \lambda_{1}=\lambda_{2}=\lambda_{3}=\lambda_{4}=0 "$, the calculated value of the relevant $F$-statistic being 3.132771 for the joint significance of the hypothesis is compared to the critical upper values bounds at the 5 percent level of significance. Comparing the value of the F-statistic of 3.132771 to the critical value of the lower bound $\mathrm{I}(0)=2.79$ and upper bound $\mathrm{I}(1)=3.67$ indicates that result of testing the null hypothesis of "non-existing of the long-run relationship" in the U.S. futures markets is inconclusive.

\section{Discussions of the Empirical Results}

The endogenous search process for breaks in the relationship between the gasoline futures price and the crude oil futures price using Perron's (1997) endogenous unit root test function with the intercept, slope, and the trend dummy found that the relationship between these two futures prices experienced a break in January 28, 2011. To account for this structural break, this investigation introduced a dummy variable and assigned the value of 1 from January 28, 2011 onward and 0 elsewhere over the sample period. Econometrically, this introduction of the dummy variable precipitated the generation of the interaction term between 
the dummy variable and the crude oil futures price.

The estimation results of the Autoregressive Distributed Lag model, ARDL (3, 1, 0, 0), represented by equation (2) reveal that the short-run pass-through rate of the price of the crude oil futures price is $\delta_{0}+\rho_{0}+\pi_{0}=$ 0.871036 .

Based on the Akaike information criterion, the longest lag retained by the estimation process for the gasoline futures price is $3\left(g a s_{-3}\right)$ and for the crude oil futures price is $1\left(w t i_{-1}\right)$. These findings suggest that the traders in the U.S. futures markets considered the trading price of the gasoline futures price three weeks back in determining their current trading price; while these traders took up to only one week to respond to the shock in the price of the crude oil futures price completely. Based on the estimation resulted reported in exhibit 3, the calculated long-run pass-through rate of the crude oil futures price is $\Phi=-0.2440894$.

Finally, as to the long-term relationship between the gasoline futures price $g a s_{t}$ and the crude oil futures price $w t i_{t}$, this study investigates this issue by testing the above stated null hypothesis $H_{0}: \lambda_{1}=\lambda_{2}=\lambda_{3}=\lambda_{4}=0$. The result of the testing procedure testing this hypothesis of no long-term relationship is inconclusive, failing to establish a long-run relationship between the gasoline futures price gas $s_{t}$ and the crude oil futures price, $w t i_{t}$, in the U.S. futures markets.

\section{CONCLUDING REMARKS}

Historically, since the industrial revolution, industrialized nations have had a relatively inelastic demand for petroleum products used both for energy and lubrication. Given this inelasticity of demand, prices are disproportionately determined by changes in supply and are therefore acutely subject to supply disruptions. Although unconventional gas production had been growing since the early 1980s, hydraulic fracturing technology had not been perfected or scaled to the point where full commercial deployment was competitive without subsidy. Shale gas production relied on the Section 29 production tax credit and on developers like Mitchell Energy charging a premium for gas resources.

Additionally, since the early 2000s, some large hedge funds have speculated on petroleum prices using derivative instruments having crude oil as the underlying commodity. Increases in prices could be partially due to this speculation extending into longer term instruments. These speculators foresee increasing demand, decreasing supply, or both, leading to the long term increase in the price of oil. If speculators are wrong, current prices may actually represent a price bubble, and the price could therefore collapse. It is theoretically expected that the rising oil market could quickly reverse, if indications of declining Asian demand continue. These disruptions, coupled with limited stored gasoline supplies and the seasonality in demand, especially given American travel habits (such as holiday travel), may exacerbate the fluctuations in demand for fuels.

On the demand side, a mild recession in the early 2000s and the U.S. subprime mortgage crisis followed by the European sovereignty debt crisis caused economic recession around the globe, slowing down the demand for gasoline in the international market. This in turn depressed crude oil prices. These aforementioned events motivate this investigation to study the nature of the crude oil futures price pass-through in the U.S. since March 3, 2006 when the data is available.

To achieve the above objective, this study utilizes an Autoregressive Distributed Lag model to empirically investigate the nature of crude oil futures price pass-through in the U.S. futures markets. Estimation results suggest that, based on the Akaike information criterion, the ARDL $(3,1,0,0)$ model best fits the data. Estimation results of the ARDL (3, 1, $0,0)$ model reveal that the U.S. short-run pass-through rate of the crude oil futures price is $\delta_{0}+\rho_{0}+\pi_{0}=0.849298$ indicating that when the crude oil futures price increases by $1 \mathrm{cent}$, the gasoline futures price increases by a corresponding 0.87 cents within one week.

The empirical findings further suggest that traders in the U.S. futures market consider the trading price of gasoline futures three weeks back in determining the current futures trading price; while these same traders took 
up to only one week to respond to the shock in the crude oil futures price completely. Based on the estimation result reported in exhibit 3 , the calculated long-run pass-through rate of the crude oil futures price is $\Phi=-0.2440894$. The findings of the high short-run and negative long-run pass-through rates suggest that traders in the U.S. oil and gasoline futures markets overreact to changes in the crude oil futures price and subsequently made corrections by adjusting the futures price downward.

The testing procedure testing the null hypothesis $\quad H_{0}: \lambda_{1}=\lambda_{2}=\lambda_{3}=\lambda_{4}=0$ indicated an inconclusive result. This testing result fails to establish a long-run relationship between the gasoline futures price gas $_{t}$ and the crude oil futures price, $w t i_{t}$, in the U.S. futures markets.

As aforementioned, the effects of petroleum price fluctuations are felt worldwide and there are particular effects on the countries of Eastern Europe and Central Asia, especially since several of these countries are important oil producers, and of course all of these countries in the region are oil consumers. Additionally all are affected by the geopolitics of the region which is substantially underlain by petroleum markets. Fluctuations in crude oil prices and the concomitant effects on gasoline prices subject all countries to difficult choices in managing national expenditures, revenues, investment decisions, etc. Parallel effects challenge the private sector as well. Wide price swings may be beneficial to the speculative trader, but they are anathema to the public and private sector governing and management decision making process. Traditionally, futures markets evolved to mitigate such fluctuations. Understanding these futures markets and the nature of price reaction and price pass through lie at the center of and offer one approach to achieving more consistent, buffered, and manageable economic continuity. This paper addresses the core elements of the price dynamics of the crude oil and gasoline futures markets and hopes to advance the inquiry into assessing tools to manage a very complex market challenge, especially for the policy makers in countries of Eastern Europe, Caucasus and Central Asia.

\section{REFERENCES}

Berstein, S., and Fuentes, R. (2003). From Rate to Bank Lending Rate: The Chilean Banking Industry. LACEA Papers and Proceedings, Mexico, 30p.

Chesnes, M. (2012). Asymmetric Pass-Through in U.S. Gasoline Prices. U.S. Federal Trade Commission Bureau of Economics Working Paper No. 302. Available at SSRN: https://ssrn.com/abstract $=1629340$ or http://dx.doi.org/10.2139/ssrn.1629340.

Enders, W. (2015). Applied Econometric Time Series. 4th edition, John Wiley and Sons, Inc. Hoboken, New Jersey, USA.

International Energy Agency. (2016). Energy Policies Beyond IEA Countries - Eastern Europe, Caucasus and Central Asia 2015. https://www.iea.org/publications/.../publi cation/IDR_EasternEuropeCaucasus_2015. pdf.

Karimli, T., Jafarova, N., Aliyeva, H., and Huseynov, S. (2016). Oil Price PassThrough into Inflation: The Evidence from Oil Exporting Countries. IHEID Working Papers, Economics Section, the Graduate Institute of International Studies, Geneva, Switzerland.

Kuuskra, V.A., and Guthrie, H.D. (2002). Translating Lessons from Unconventional Gas R\&D to Geologic Sequestration Technology. Journal of Energy \& Environmental Research, Vol. 2, No. 1, US National Energy Technology Laboratory.

Pereira, C.M. and Maia-Filho, L.F. (2013). Brazilian Retail Banking and the 2008 Financial Crisis: Were the GovernmentControlled Banks that Important? Journal of Banking \& Finance, Vol. 37(7), pp. 22102215.

Perron, P. (1997). Further Evidence on Breaking Trend Functions in Macroeconomic Variables. Journal of Econometrics, Vol. 80, pp. 355-385.

Pesaran, M. H., Shin, Y., and Smith, R. (2001). Bounds Testing Approaches to the Analysis of Level Relationship. Journal of Applied Econometrics, Vol. 16, pp. 289326.

Steinsberger, N. (2011). Former Managing Engineer for Mitchell Energy. Telephone interview by Alex Tembath on December 12, 2011. 
Trembath, A., Jenkins,J. Nordhaus, T., and Shellenberger, M. (2012). Where the Shale Gas Revolution Came from: Governmnet's Role in the Development of Hydrolic Fracturing in Shales. Breakthrough Institute.

Wickens, M., Breusch, T. (1988). Dynamic specification, the long run and the estimation of transformed regression models. Economic Journal, 98, pp. 189205.

Yergin, D. (2011). The Natural Gas Revolution. From The Quest: Energy Security and the remaking of the Modern World, Published by Penguin Group, New York, NY 2011

Yellen, J.L. (2011). Commodity Prices, the Economic Outlook, and Monetary Policy. Speech at the Economic Club of New York, New York, NY, April 11.

\section{ABOUT THE AUTHOR}

Chu V. Nguyen, email: nguyenchu@uhd.edu

Dr. Chu V. Nguyen is an Associate Professor of Economics and Finance and Chair of the FAEIS Department at the Davies College of Business, University of Houston-Downtown. He earned an MA in Economics, an MS in Mathematics and a Ph.D. in Economics from the University of Cincinnati. He is also the Chairman of the Board of Directors of Tropical Star Enterprise, Inc. He served as an economist and then the Head of the Economic Analysis and Forecasting Department at the $5^{\text {th }}$ District of Federal Home Loan Bank System. He published over 85 publications in reputable US and international peer-reviewed journals. 